\title{
Reply: EU ETS and the waterbed effect
}

\author{
Grischa Perino
}

REPLYING TO K. Rosendahl Nature Climate Change https://doi.org/10.1038/s41558-019-0579-5 (2019)

Timing is crucial in the cancellation of allowances in the EU Emission Trading System (ETS). Abatement that occurs after the market stability reserve (MSR) has stopped taking in allowances can increase total emissions, but the size of the effect depends critically on highly uncertain parameters.

Rosendahl raises the interesting and valid point that anticipated future abatement induced by a policy that overlaps the EU ETS has the potential to increase total emissions by causing a drop in the price of allowances and hence less ETS-driven abatement, less banking and fewer cancellations ${ }^{1}$. The analysis in Perino ${ }^{2}$ is based on a small amount ( $1 \mathrm{t}$ of $\mathrm{CO}_{2}$ equivalent) abated at a particular point in time and focuses on 'direct effects'-deliberately ignoring 'indirect' effects induced by changes in the price path of allowances ${ }^{2}$. Hence, it neither captures the effects of permanent abatement measures nor the potential increase in cumulative emissions if abatement due to overlapping policies occurs after the MSR has stopped taking in allowances but before the total number of allowances in circulation or 'bank' drops to zero, as addressed by Rosendahl. Abatement that occurs before the MSR stops taking in allowances increases the expected total cancellations. Anticipated abatement after the bank is depleted has no impact on current prices and hence on cancellations, as intertemporal arbitrage breaks down once banking ceases. The extensions put forward by Rosendahl that concern the time between these phases are plausible and justified. They reinforce the more general point that timing of abatement matters greatly in the reformed EU ETS $\mathrm{ET}^{1,3-5}$.

The scope of anticipated future abatement to increase cumulative emissions depends on the points in time when the MSR is predicted to stop taking in allowances and when the bank is depleted. However, predictions of the timing of these events vary by decades ${ }^{3,6}$. These predictions in turn depend mainly on assumptions regarding the underlying time trend in baseline emissions, marginal abatement cost curves and discount rates. The intuition is as follows: anticipated abatement that occurs at any point before the bank is depleted induces a reduction in the allowance price path due to the corresponding drop in the scarcity of allowances. In turn, polluting firms increase their emissions and reduce banking over the entire banking phase. If anticipated abatement from overlapping policies is late, the bank is more back-loaded and fewer allowances enter the MSR and are eventually cancelled. The size of this effect is determined by how much of the banking phase (that is, before the bank drops to zero) the MSR is taking in allowances for. If the MSR is active for only a small portion of the banking phase, the impact of the price change on cancellations will also be small. If the MSR is active for a greater share of the banking phase, the opposite holds true. As predictions on timing differ widely in the emerging literature on the MSR, so would the impact of the effects identified by Rosendahl. My own models ${ }^{2,6}$ suggest that the effect of late anticipated abatement on cancellations would be small due to the predicted timing and hence essentially due to the admittedly ad hoc assumptions on the evolution of baseline emissions.
In principle, a policy that is sufficiently back-loaded in terms of anticipated abatement-and the German coal phase-out might be a case in point-could have a negative impact on cumulative emissions. However, establishing effect sizes is a quantitative and eventually empirical question beyond the scope of this Reply, and should be looked at in more detail in future work. The identification of plausible trajectories of baseline emissions (that is, how emissions would evolve over the coming decades in the absence of any climate policy), long-term marginal abatement cost curves and discount rates of market participants is crucial, but not trivial: the former is a purely hypothetical object and the two latter components are likely to be affected by companies' expectations of future policies ${ }^{7-10}$.

In conclusion, I consider the sizes of any increases in long-term emissions that are induced by anticipated future abatement to be highly uncertain and potentially quite small. Yet they could occur, and research on quantification is desirable.

Received: 21 May 2019; Accepted: 20 August 2019;

Published online: 25 September 2019

\section{References}

1. Rosendahl, K. E. EU ETS and the waterbed effect. Nat. Clim. Change https:// doi.org/10.1038/s41558-019-0579-5 (2019).

2. Perino, G. New EU ETS Phase 4 rules temporarily puncture waterbed. Nat. Clim. Change 8, 262-264 (2018).

3. Quemin, S. \& Trotignon, R. Intertemporal Emissions Trading and Market Design: An Application to the EU ETS Working Paper No. 316 (Grantham Research Institute on Climate Change and the Environment, 2019).

4. Gerlagh, R. \& Heijmans, R. J. R. K. Climate conscious consumers and the buy, bank, burn program. Nat. Clim. Change 9, 431-433 (2019).

5. Perino, G. et al. Understanding Overlapping Policies: Internal Carbon Leakage and the Punctured Waterbed Working Paper No. 25643 (NBER, 2019); https:// www.nber.org/papers/w25643

6. Perino, G. \& Willner, M. EU-ETS Phase IV: allowance prices, design choices and the market stability reserve. Clim. Policy 17, 936-946 (2017).

7. Fuss, S. et al. A framework for assessing the performance of cap-and-trade systems: insights from the European Union Emissions Trading System. Rev. Environ. Econ. Policy 12, 220-241 (2018).

8. Kollenberg, S. \& Taschini, L. Dynamic supply adjustment and banking under uncertainty in an emission trading scheme: the market stability reserve. Eur. Econ. Rev. 118, 213-226 (2019).

9. Hepburn, C. et al. The economics of the EU ETS market stability reserve. J. Environ. Econ. Manage. 80, 1-5 (2016).

10. Perino, G. \& Willner, M. Rushing the impatient: allowance reserves and the time profile of low-carboninvestments. Environ. Resour. Econ. https://doi. org/10.1007/s10640-019-00350-x (2019).

\section{Competing interests}

The author declares no competing interests.

\section{Additional information}

Correspondence and requests for materials should be addressed to G.P.

Reprints and permissions information is available at www.nature.com/reprints.

Publisher's note Springer Nature remains neutral with regard to jurisdictional claims in published maps and institutional affiliations.

(C) The Author(s), under exclusive licence to Springer Nature Limited 2019 